\title{
Oxidative dehydrogenation of 1-butene to butadiene over carbon nanotube catalysts
}

\author{
Xi Liu, Dang Sheng Su*, Robert Schlögl \\ Fritz-Haber-Institut der Max-Planck-Gesellschaft, Faradayweg 4-6, D-14195 Berlin, Germany \\ * Corresponding author: Fax: +49 (030) 84134405, E-mail address: dangsheng@fhi-berlin.mpg.de (D.S. Su).
}

The applications of carbon nanotubes (CNTs) as catalysts have attracted much interests in catalysis community due to their unique porous microstructure and chemical properties. One of the promising results is the use of CNTs in the oxidative dehydrogenation (ODH) of ethylbenzene to styrene [1,2]. However, only few works were reported on the use of CNTs or other carbonaceous materials to catalyze the ODH of light hydrocarbons [3]. Despite of a wide availability and low price of light olefins, it is a constructive investigation on reaction mechanism by using straight chain aliphatic compound as reactant in the ODH over the carbonaceous catalysts.

We report here the first application of CNTs as catalysts in the ODH of 1-butene to butadiene. The catalytic performance of the CNTs is remarkable high and stable, superior to that of activated carbon and iron oxide. The characterization of the CNTs before and after reaction is made to test the hypothesis that oxygen functional groups are the active sites for the ODH reaction.

Multi-walled CNTs (Applied Science Co.), produced by catalytic hydrocarbon decomposition, were used in the current study. The diameter of the CNTs ranges from $50 \mathrm{~nm}$ to $200 \mathrm{~nm}$. Two kinds of acid-washed activated carbons were used for comparison. One is supplied by the Alfa Aesar Co. (Germany) and the other is supplied by the COMBICAT research centre (University of Malaya, Malaysia). The CNTs and the activated carbons (Alfa Aesar Co. and COMBICAT) are labelled CNT, AC-1 and AC-2, respectively.

Catalytic tests were carried out at atmospheric pressure and $400{ }^{\circ} \mathrm{C}$ in a continuous-flow fixed-bed quartz reactor using $180 \mathrm{mg}$ catalysts. The reactant gases are fed through mass flow controllers with a total flow rate of $15 \mathrm{ml} / \mathrm{min}$. The first experiment was conducted with an oxygen/1-butene ratio of 1 and $1.32 \mathrm{~mol} \%$ oxygen for $50 \mathrm{~h}$. Then, we increased the oxygen/1-butene ratio to 2 and maintained the reaction for $20 \mathrm{~h}$. BET surface area measurements, Temperature-prprogrammed oxidation (TPO) and X-ray photoelectron spectroscopy (XPS) were used to study the physicochemical properties of CNT before and after reaction.

The performance of CNT along with the reaction time is displayed in Fig. 1. During the reaction for $70 \mathrm{~h}$, carbon balance around $100 \%$ was always obtained. The by-products are mainly $\mathrm{CO}$ and $\mathrm{CO}_{2}$ and only the trace amount of propene could be detected. After a $20 \mathrm{~h}$ induction period, CNT stably catalyzed the oxidative dehydrogenation of 1-butene. The conversion and butadiene yield stayed at around $45 \%$ and $29 \%$, respectively. A decrease in $\mathrm{CO}_{2}$ selectivity during the induction period could be related with the activation of CNT. After the oxygen/1-butene ratio was increased from 1 to 2 , a higher conversion of $72 \%$ and yield of $43 \%$ was obtained while selectivity remained almost constant at about $60 \%$. The unchanged selectivity indicates that an excess of oxygen does not change the selective sites on the surface of CNT.

The catalytic performance of the carbonaceous materials is given in Table 1. A comparison of catalytic performance is also given between the carbonaceous materials with iron catalyst from a literature, which indicated a wide availability of the iron-based catalysts in the conventional ODH of butane or butene [4]. The butadiene formation rate obtained with CNT is more than 10 times higher than that with the activated carbons and the catalytic performance of CNT is also superior to that of iron oxide, suggesting the promising future of CNT in the ODH of light olefins.

The BET area of the carbonaceous materials before and after reaction is also given in Table 1. The significant decrease in the BET area of the activated carbons can be attributed to the carbon deposition and blockage of micropores [5]. A slight increase in the BET area of CNT could be attributed to the combustion of amorphous carbon. After an initial period of 20 minutes, the carbon balance kept at 100\% 
suggesting that the combustion of CNT or carbon deposition from hydrocarbons are negligible during the steady state.

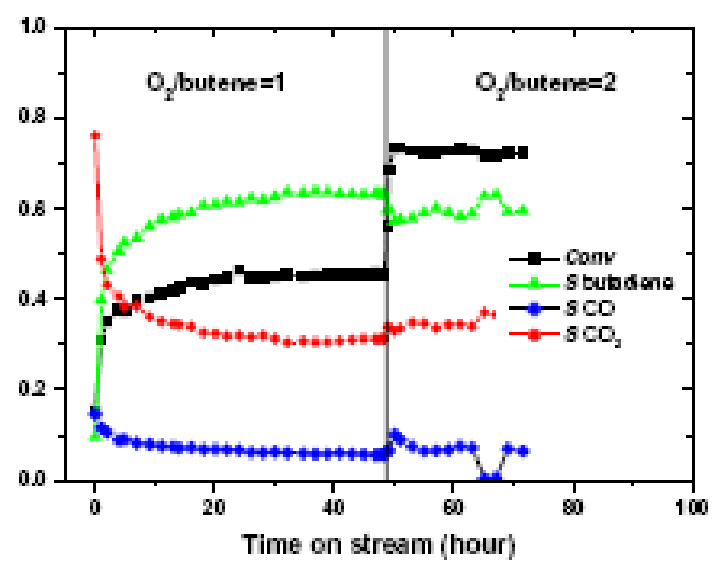

Fig. 1: Performance of CNT in the ODH of 1-butene with different oxygen/butene molar ratios as function of reaction time( butene conversion, $\boldsymbol{\Lambda}$ selectivity to butadiene, $\bullet$ selectivity to $\mathrm{CO}, \bullet$ selectivity to $\mathrm{CO}_{2}$ ).
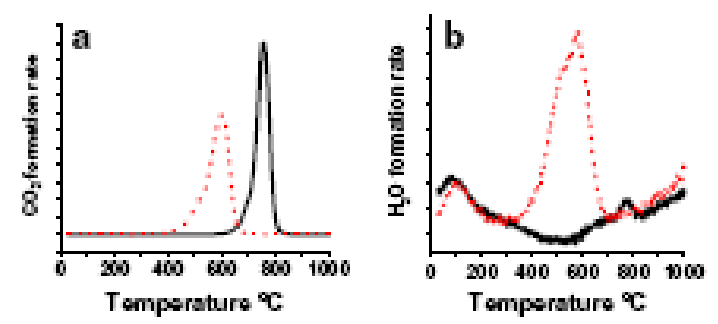

Fig. 2: The gas evolution of TPO spectra of the fresh (solid line) and used CNT (dot line) to reaction test: (a) $\mathrm{CO}_{2}$ signal; (b) $\mathrm{H}_{2} \mathrm{O}$ signal.

The TPO spectra of CNT before and after reaction (Fig. 2) illustrate that the used CNT has higher concentration of hydroxyl functional groups than the pristine CNT. The oxidative gasification temperature of the pristine CNT is $600{ }^{\circ} \mathrm{C}$ while that of the used CNT is $400{ }^{\circ} \mathrm{C} \mathrm{(Fig.} \mathrm{2a).} \mathrm{The} \mathrm{lower}$ gasification temperature of the used $\mathrm{CNT}$ is attributed to the higher functionalization degree of graphene edges [6]. The above finding is affirmed by the $\mathrm{H}_{2} \mathrm{O}$ profiles (Fig. 2b). At about $100{ }^{\circ} \mathrm{C}$, the TPO traces for water (Fig. 2b) are similar for both CNT samples, which can be attributed to desorption of water. For the fresh CNT, the water formation rate decreases and no obvious peak is observed in the temperature region of $300-700{ }^{\circ} \mathrm{C}$. In contrast, for the used CNT, a significant formation of water was observed between $300{ }^{\circ} \mathrm{C}$ and $700{ }^{\circ} \mathrm{C}$, which is assigned to the decomposition of hydroxyl functional groups.

The increase in amount of oxygen functional groups is confirmed by XPS quantification (Fig. 3) and by IR experiment (Fig. S1). The concentration of oxygen atoms on the surface of CNT increases from $3 \%$ to $6 \%$ after the catalytic test. Fig. $3 \mathrm{a}$ and $3 \mathrm{~b}$ show the $\mathrm{C} 1 \mathrm{~s}$ and $\mathrm{O} 1 \mathrm{~s}$ XPS spectra of the fresh and used CNT. All the $\mathrm{C}$ 1s spectra contain a typical graphitic peak at around $284.8 \mathrm{eV}$. However, clear changes in the $\mathrm{O}$ 1s spectra are observed indicating the difference in functionalization between the fresh and used CNT. The deconvolution of $\mathrm{O}$ 1s spectra is shown in Fig. $3 \mathrm{~b}$. The $\mathrm{O} 1 \mathrm{~s}$ peak mainly has three contributions that can be interpreted as: carbonyl $/ \mathrm{C}=\mathrm{O}$ (around 531.1-531.8 eV), hydroxyl $/ \mathrm{C}-\mathrm{OH}$ (around $533.3 \mathrm{eV}$ ) and water (around $536.1 \mathrm{eV}$ ). Obviously the peak at $533.3 \mathrm{eV}$ increases more than the peak at $531.0 \mathrm{eV}$, which is correlated with the high formation rate of water observed in the TPO spectrum of the used CNT and was also reported in previous work [7].

The characterization indicates that the catalytic behaviour of CNT is related to the oxygen functional groups. Only quinine groups can be the active sites as they are stable at temperature used in this reaction. Quinone groups are also suggested to be the active functional groups in the ODH of ethylbenzene to styrene $[1,2,7]$. The fresh CNT contains $3 \%$ oxygen atomic concentration and exhibits less activity for the ODH. This also confirms that not all oxygen groups are active sites in the ODH. The possible catalytic 
process is proposed to follow the following steps: the CNT is functionalized gradually by the oxygen gas and stable quinone groups form on the surface of CNT; a butene molecular is adsorbed on the surface of functionalized CNT; consecutively the b-elimination happens and the quinone functional group is reduced to a hydroxyl functional group; finally the formed butadiene molecular is desorped and the hydroxyl functional group is oxidized to a quinone group by adsorbed oxygen [1].

Based on the above results, we can conclude that the commercial CNTs display a good stability and a promising catalytic activity for the $\mathrm{ODH}$ reaction of 1-butene to butadiene. CNTs are highly functionalized during the reaction. The increase in amount of oxygen functional groups during the reaction process suggests that the quinone/hydroxyl functional groups could be redox could be the active sites for the ODH reaction.

Table 1 - The catalytic properties of three kinds of carbon materials and iron oxide catalyst

$\begin{array}{llllllll}\text { Catalysts } & \mathrm{O}_{2} \text { /butane } & \text { Con. (\%) } & \begin{array}{l}\mathrm{S}_{\text {butadiene }} \\ (\%)\end{array} & \text { Yield (\%) } & \text { BET surface } & \text { area }\left(\mathrm{m}^{2} / \mathrm{g}\right) & \begin{array}{l}\text { Butadiene formation } \\ \text { rate }\left(\mathrm{x} 10^{-5} \mathrm{~mol} \cdot \mathrm{h} / \mathrm{m}^{2}\right)\end{array} \\ & & & & & \text { Before reaction } & \text { After reaction } & \\ \mathrm{CNT} & 1 & 45 & 63 & 28 & 42 & 58 & 0.75 \\ & 2 & 72 & 60 & 43 & & 311 & 0.062 \\ \mathrm{AC}-1 & 1 & 31 & 42 & 13 & 837 & & 0.077 \\ & 2 & 45 & 36 & 16 & & 334 & 0.049 \\ \mathrm{AC}-2 & 1 & 24 & 46 & 11 & 1081 & & 0.062 \\ & 2 & 36 & 38 & 14 & & & \end{array}$
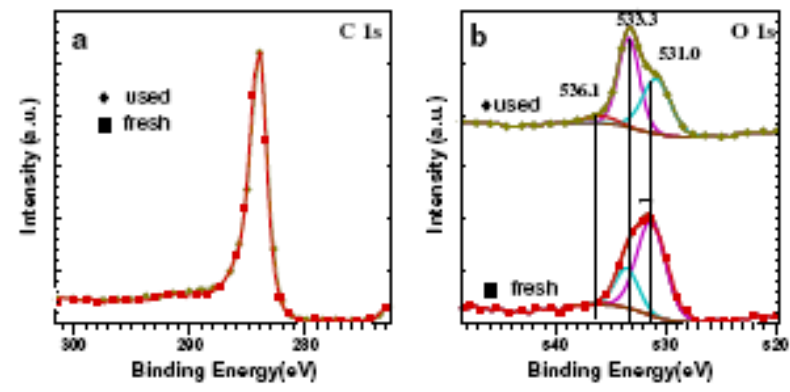

Fig. 3: The XPS spectra of the fresh (匹) and used CNT (•): (a) C 1s spectra; (b) O 1s spectra.

\section{Acknowledgements}

The authors are grateful for the support provided by the European Union FP6 program (CANAPE project). X. Liu thanks Dr B. Kubias, Dr D. Wang and Dr L. Wang for helpful discussions.

\section{References}

[1] Mestl G, Maksimova N, Keller N, Roddatis VV, Schlögl R., Carbon nanofilaments in heterogeneous catalysis: an industrial application for new carbon materials., Angew Chem Int Ed 2001;40(11):2066-

[2] Su DS, Maksimova N, Delgado JJ, Keller N, Mestl G, Ledoux MJ,et al.,Nanocarbon in selective oxidative dehydrogenation reaction., Catal Today 2005;102-103:110.

[3] Sui ZJ, Zhou JH, Dai YC, Yuan WK., Oxidative dehydrogenationof propane over catalysts based on carbon nanofibers, CatalToday 2005;106:90-4.

[4] Toledo JA, Valenzuela MA, Armendariz H, Aguilarrios G,Zapada P, Montoya A, et al., Oxidative dehydrogenation of 1-butene to butadiene on alpha- $\mathrm{Fe}_{2} \mathrm{O}_{3} / \mathrm{ZnAl}_{2} \mathrm{O}_{4}$ and $\mathrm{ZnFe}_{\mathrm{x}} \mathrm{Al}_{2-\mathrm{x}} \mathrm{O}_{4}$ catalysts., Catal Lett 1995;30:279-88.

[5] Pereira MFR, Orfao JJM, Figueiredo JL., Oxidative dehydrogenation of ethylbenzene on activated carbon catalysts 3. Catalyst deactivation., Appl Catal A: Gen 2001;218:307-18.

[6] Aso H, Matsuoka K, Sharma A, Tomita A.,Evaluation of size of graphene sheet in anthracite by a temperatureprogrammed oxidation method., Energy Fuel 2004;18:1309-14.

[7] Macia-Agullo JA, Cazorla-Amoros D, Linares-Solano A, Wild U, Su DS, Schlögl R., Oxygen functional groups involved in the styrene production reaction detected by quasi in situ XPS, Catal Today 2005;102:248-53. 